\title{
Comparison of Coxiella burnetii Shedding in Milk of Dairy Bovine, Caprine, and Ovine Herds
}

\author{
A. Rodolakis, ${ }^{\star 1}$ M. Berri, ${ }^{\star}$ C. Héchard, ${ }^{\star 2}$ C. Caudron, ${ }^{\star 3}$ A. Souriau, ${ }^{\star}$ C. C. Bodier, ${ }^{\star}$ B. Blanchard, $\dagger$ \\ P. Camuset, $¥$ P. Devillechaise,§ J. C. Natorp,|| J. P. Vadet,\# and N. Arricau-Bouvery ${ }^{\star 4}$ \\ *INRA, UR1282, Infectiologie Animale et Santé Publique, Centre de recherche de Tours, 37380 Nouzilly, France \\ †Adiagène, 38 rue de Paris, 22000 Saint Brieuc, France \\ $\ddagger$ SNGTV, 5 rue Moufle, 75011 Paris, France \\ $\S$ La Condamine, 26400 Crest, France \\ ||Le Bourg, 64430 St Etienne de Baigorry, France \\ \#24 rue Carnot, 76190 Yvetot, France
}

\section{ABSTRACT}

The shedding of Coxiella burnetii in bovine, caprine, and ovine milk was measured using PCR, in 3 herds for each species, the bulk tank milk samples of which were positive at the time of their selection. Milk samples of 95 cows, 120 goats, and 90 ewes were sampled over $16 \mathrm{wk}$, as was the bulk tank milk. The shedding of $C$. burnetii in vaginal mucus and feces was checked at the beginning of the experiment and 2 mo later. The clinical signs in the selected herds as well as the duration and the shedding routes differed among the 3 species. The cows were asymptomatic and shed $C$. burnetii almost exclusively in milk. In one of the caprine herds, abortions due to $C$. burnetii were reported. The goats excreted the bacteria mainly in milk. In contrast, the ewes, which came from flocks with abortions due to $\mathrm{Q}$ fever (C. burnetii infection), shed the bacteria mostly in feces and in vaginal mucus. This could explain why human outbreaks of $\mathrm{Q}$ fever are more often related to ovine flocks than to bovine herds. These excretions did not seem more frequent when the samples were taken close to parturition. The samples were taken from 0 to $421 \mathrm{~d}$ after parturition in bovine herds and from 5 to $119 \mathrm{~d}$ and 11 to $238 \mathrm{~d}$ after parturition in the caprine and ovine herds, respectively. The shedding in milk was sometimes intermittent, and several animals shed the bacteria but were negative by ELISA: $80 \%$ of the ewes were seronegative, underscoring the lack of sensitivity of the ELISA tests available for veterinary

\footnotetext{
Received December 4, 2006.

Accepted August 27, 2007.

${ }^{1}$ Corresponding author: Annie.Rodolakis@tours.inra.fr

${ }^{2}$ Present address: VigiCell SAS, Institut André Lwoff (CNRS), 7 rue Guy Moquet - BP 8, 94801 Villejuif Cedex, France.

${ }^{3}$ Present address: CEVA Santé Animale La Ballastière, BP 126 33501, Libourne Cedex, France.

${ }^{4}$ Present address: INRA Domaine de la Grande Ferrade UMR GDPP, 33883 Villenave D'Oron Cedex, France.
}

diagnosis. The detection of antibodies in milk seems more sensitive than it is in serum.

Key words: Q fever, dairy cow, dairy goat, dairy ewe

\section{INTRODUCTION}

$\mathrm{Q}$ fever, a zoonosis caused by the obligate intracellular bacterium Coxiella burnetii, is endemic throughout the world and affects arthropods, birds, pets, domestic and wild mammals, and humans (Maurin and Raoult, 1999). In humans, the acute disease appears mostly as a flu-like, usually self-limiting illness accompanied by myalgia and severe headache. Complications such as pneumonia or hepatitis may occur. Endocarditis in patients suffering from valvulopathy, and premature delivery or abortion in pregnant women are the main severe manifestations of the chronic evolution of the disease (Maurin and Raoult, 1999). The source of human infection is often unknown, although sheep and goats are more frequently related to outbreaks of human Q fever than are other animal species (Lyytikäinen et al., 1998; Tissot-Dupont et al., 1999; Berri et al., 2003b). In livestock, C. burnetii can induce reproductive disorders such as abortion, stillbirth, and delivery of weak and unviable newborns (Palmer et al., 1983; Moore et al., 1991; Bildfell et al., 2000). Metritis and infertility due to $C$. burnetii infection are more frequent in bovine than in other ruminant species (Lang, 1990; To et al., 1998). At parturition of infected females, great numbers of Coxiella are shed into the birth products, urine, feces, and milk of females that have aborted (Hatchette et al., 2001; Arricau-Bouvery et al., 2003; Masala et al., 2004) as well as of those with normal parturition (To et al., 1995; Berri et al., 2005; Kim et al., 2005). The main route of $C$. burnetii infection is inhalation of contaminated aerosols or dusts containing the microorganism shed from infected animals (Welsh et al., 1957; Tissot-Dupont et al., 1999). Because $C$. burnetii is very stable in the environment, close contact 
Table 1. Schedule of sampling in naturally infected herds

\begin{tabular}{llllllllll}
\hline & \multicolumn{7}{c}{ Week } \\
\cline { 2 - 10 } Sample & 0 & 1 & 2 & 3 & 4 & 6 & 8 & 12 & $16^{1}$ \\
\hline Milk & + & + & + & + & + & + & + & + & + \\
Vaginal mucus & + & - & - & - & - & - & + & - & - \\
Feces & + & - & - & - & - & - & + & - & - \\
Blood & + & - & - & - & - & - & + & - & - \\
\hline
\end{tabular}

${ }^{1}$ The ovine flocks B, H, and $\mathrm{M}$ were sampled at wk 14, and the caprine herds $\mathrm{T}$ and $\mathrm{R}$ at wk 17 instead of wk 16. The control herds were sampled only at wk 0 .

with the herd is not required. Oral transmission by ingestion of contaminated raw milk or dairy products could lead to seroconversion and perhaps, in a few cases, to Q fever (Benson et al., 1963; Fishbein and Raoult, 1992). However, related policy in France is currently focused only on the trade of raw milk and its products. When clinical signs of $\mathrm{Q}$ fever (abortion) have been diagnosed in a herd, the sale of raw milk and raw milk dairy products is forbidden for $1 \mathrm{yr}$, the milk of the aborted female must be discarded, and that of the remainder of the flock must be pasteurized. Nevertheless, an accurate description of the kinetics of $C$. burnetii shedding in milk does not exist because, before the development of PCR (Willems et al., 1994; Muramatsu et al., 1996; Berri et al., 2000), the detection of C. burnetii in milk relied on insensitive methods and was difficult (Woernle et al., 1985; Rehácek et al., 1998). The aim of this study was to follow C. burnetii shedding over $4 \mathrm{mo}$, into the milk of bovine, ovine, and caprine herds with or without clinical signs, to determine the relative importance of milk among the different routes of shedding.

\section{MATERIALS AND METHODS}

\section{Animals}

Bovine, ovine, and caprine herds were selected after serological analysis of 10 serum samples and PCR analysis of bulk tank milk. "Positive" herds had a PCRpositive bulk tank milk sample and at least 2 ELISApositive samples among the 10 serum samples taken. In "negative" herds, the bulk tank milks were negative by PCR and the 10 serum samples were negative by ELISA. In each species, 3 positive herds and 1 negative control herd were selected to study the kinetics of $C$. burnetii shedding.

\section{Collection of Samples}

Thirty females were sampled from the selected herds weekly for $4 \mathrm{wk}$ and then according to schedule for the following 3 mo (Table 1). In caprine herd D (Table 2), 60 goats were tested: 30 goats were first tested at wk 0,1 , and 2 . Only 1 of them was positive by PCR at wk 2 , whereas the bulk tank milk samples became PCR

Table 2. Selected bovine herds

\begin{tabular}{|c|c|c|c|c|c|}
\hline \multirow[b]{2}{*}{ Herd } & \multicolumn{3}{|c|}{ Date (mon/day/year) of: } & \multicolumn{2}{|c|}{$\begin{array}{l}\text { Delay from parturition } \\
\text { to the beginning } \\
\text { of sampling }(d)\end{array}$} \\
\hline & Selection & Beginning & End & Minimum & Maximum \\
\hline \multicolumn{6}{|c|}{ Bovine } \\
\hline $\mathrm{E}$ & $01 / 07 / 2003$ & $03 / 24 / 2003$ & $03 / 24 / 2003$ & 34 & 421 \\
\hline $\mathrm{F}$ & $01 / 07 / 2003$ & 08/05/2003 & $11 / 25 / 2003$ & 2 & 309 \\
\hline $\mathrm{L}$ & $12 / 17 / 2002$ & $10 / 06 / 2003$ & $01 / 26 / 2004$ & 0 & 295 \\
\hline $\mathrm{V}$ & $12 / 17 / 2002$ & 02/17/2003 & 06/09/2003 & 7 & 122 \\
\hline \multicolumn{6}{|c|}{ Caprine } \\
\hline $\mathrm{D}$ & $01 / 21 / 2003$ & 09/23/2003 & $02 / 03 / 2004$ & 5 & 87 \\
\hline $\mathrm{F}$ & $02 / 20 / 2003$ & 08/19/2003 & 08/19/2003 & 70 & 270 \\
\hline $\mathrm{R}$ & 02/20/2003 & 05/05/2003 & 09/01/2003 & 14 & 76 \\
\hline $\mathrm{T}$ & $02 / 20 / 2003$ & $04 / 06 / 2003$ & 08/04/2003 & 20 & 71 \\
\hline \multicolumn{6}{|c|}{ Ovine } \\
\hline B & $02 / 25 / 2004$ & 03/16/2004 & $06 / 21 / 2004$ & 76 & 126 \\
\hline $\mathrm{Fi}$ & $06 / 04 / 2004$ & 06/08/2004 & 06/08/2004 & 40 & 209 \\
\hline $\mathrm{H}$ & $02 / 25 / 2004$ & 03/15/2004 & $06 / 21 / 2004$ & 11 & 743 \\
\hline M & $02 / 25 / 2004$ & 03/16/2004 & $06 / 21 / 2004$ & 36 & 125 \\
\hline
\end{tabular}


Table 3. Comparison of the different protocols $(\mathrm{A}, \mathrm{B}, \mathrm{C})^{1}$ of treatment of milk samples before DNA extraction by use of a QIAmp DNA mini kit (Qiagen, Courtaboeuf, France)

\begin{tabular}{|c|c|c|c|c|c|c|c|c|c|c|c|c|c|c|c|c|c|c|}
\hline \multirow[b]{3}{*}{ Herd } & \multicolumn{18}{|c|}{ Week } \\
\hline & \multicolumn{3}{|c|}{3} & \multicolumn{3}{|c|}{4} & \multicolumn{3}{|c|}{6} & \multicolumn{3}{|c|}{8} & \multicolumn{3}{|c|}{12} & \multicolumn{3}{|c|}{16} \\
\hline & $\mathrm{C}$ & B & $\mathrm{A}$ & $\mathrm{C}$ & B & A & C & B & A & C & B & $\mathrm{A}$ & $\mathrm{C}$ & B & A & $\mathrm{C}$ & B & A \\
\hline Bovine & & & & & & & & & & & & & & & & & & \\
\hline $\mathrm{F}$ & $\_^{2}$ & NT & - & - & NT & NT & - & + & + & NT & NT & + & + & + & + & + & + & + \\
\hline & + & NT & - & - & + & - & - & + & + & + & + & + & - & + & + & - & + & + \\
\hline $\begin{array}{c}\text { D } \\
\text { Ovine }\end{array}$ & + & + & + & + & + & + & + & + & + & + & + & + & + & + & + & + & - & + \\
\hline B & NT & NT & NT & + & + & + & - & + & - & NT & NT & - & NT & NT & NT & $\mathrm{NT}$ & NT & - \\
\hline $\mathrm{H}$ & NT & NT & $\mathrm{NT}$ & + & + & + & + & + & + & NT & NT & + & NT & NT & + & $\mathrm{NT}$ & NT & - \\
\hline M & NT & NT & NT & + & + & + & + & + & + & NT & NT & + & NT & NT & + & NT & NT & - \\
\hline
\end{tabular}

${ }^{1} \mathrm{~A}=$ DNA extraction from $400 \mu \mathrm{L}$ of milk; B = DNA extraction from the cream obtained after centrifugation of $1 \mathrm{~mL}$ of milk; $\mathrm{C}=$ DNA extraction from the pellet obtained after centrifugation of $1 \mathrm{~mL}$ of milk.

${ }^{2}$ PCR results of each protocol of DNA extraction: - = PCR negative; + = PCR positive; NT = not tested.

positive at wk 1 and remained positive at wk 2 . Hence, we decided to select 30 other goats. For this, 5 pools of 10 milk samples were tested. They were taken from goats, the milk of which was added to the tank during wk 0 and 1 . Three of these 5 pools were positive, and the 30 corresponding goats were selected to be tested from wk 6 to 16 .

\section{Preparation of DNA for PCR Assay}

Samples were collected and treated as previously described (Berri et al., 2003a) except for milk samples. Briefly, genital swab samples were extensively washed in $1 \mathrm{~mL}$ of PBS, and $200 \mu \mathrm{L}$ of this solution was used for DNA purification using a QIAmp DNA mini kit (Qiagen, Courtaboeuf, France). About $20 \mathrm{mg}$ of fecal sample was treated directly with proteinase $\mathrm{K}$ (final concentration $200 \mu \mathrm{g} / \mathrm{mL}$ ) in ATL buffer of QIAmp Tissue Kit (Qiagen) for 30 min at $70^{\circ} \mathrm{C}$. For milk samples, $C$. burnetii DNA was extracted using 3 different protocols (A, B, and C) to optimize the sensitivity of the detection (Table 3 ). In protocol A, $400 \mu \mathrm{L}$ of each milk sample was treated directly to purify Coxiella DNA. In protocols B and C, as previously described (Berri et al., 2003a), $1 \mathrm{~mL}$ of milk was centrifuged at $13,000 \times g$ for $1 \mathrm{~h}$. The DNA from the cream was purified using a QIAmp DNA mini kit (protocol B), whereas the pellet was washed twice with sterile water before DNA purification using a QIAmp DNA mini kit (protocol C). Protocol $\mathrm{C}$ was used to select bovine and caprine herds and to follow the kinetics of shedding in caprine herds $\mathrm{R}$ and $\mathrm{T}$ and bovine herd V. Protocol C was also used to purify DNA from the milk samples taken at wk 0 to 4 from bovine herd F. Protocols A and C were used on milk samples collected at wk 6 from bovine herd F, and then protocol A was used to select the ovine herds and for all the individ- ual milk samples. The 3 protocols were used in parallel for bulk tank milk samples.

A negative control (the extraction control), in which $200 \mu \mathrm{L}$ of sterile water was extracted using the QIAmp tissue kit, was added to each DNA extraction series to check for possible DNA contamination.

The PCR assay was performed using an Adiavet Cox PCR detection kit (Adiagene, Saint Brieuc, France) according to the manufacturer's instructions. Briefly, 2 $\mu \mathrm{L}$ of DNA extract was mixed with $48 \mu \mathrm{L}$ of ready-touse $\mathrm{A} 1$ and $\mathrm{A} 2$ reagent mix (Adiavet, Adiagène). Amplification was conducted in a Biometra thermocycler (Biometra, Göttingen, Germany) and consisted of an initial cycle of $5 \mathrm{~min}$ at $95^{\circ} \mathrm{C}$ followed by 45 cycles of $15 \mathrm{~s}$ at $94^{\circ} \mathrm{C} ; 30 \mathrm{~s}$ at $62^{\circ} \mathrm{C}$; and $40 \mathrm{~s}$ at $72^{\circ} \mathrm{C}$. Final extension was performed for $10 \mathrm{~min}$ at $72^{\circ} \mathrm{C}$. Detection of amplified products was performed on $1.3 \%$ agarose gel in $1 \times$ Trisborate-EDTA buffer.

\section{ELISA Assay}

The ELISA was performed as previously described (Berri et al., 2001) on serum and milk samples using an ELISA kit (Chekit, Bommeli, Idexx Laboratories, Broomfield, CO) based on C. burnetii phase I and phase II purified antigens. The serum samples were diluted 1:400, and the milk samples were diluted 1:5 after a centrifugation step at 17,600 $\times \mathrm{g}$ for $10 \mathrm{~min}$. As recommended by the manufacturer, animals were considered to be positive by ELISA if they had an optical density (OD) percentage of 50 or more. They were considered negative by ELISA if the OD percentage was $<40$, and doubtful if it was between 40 and 50 . 


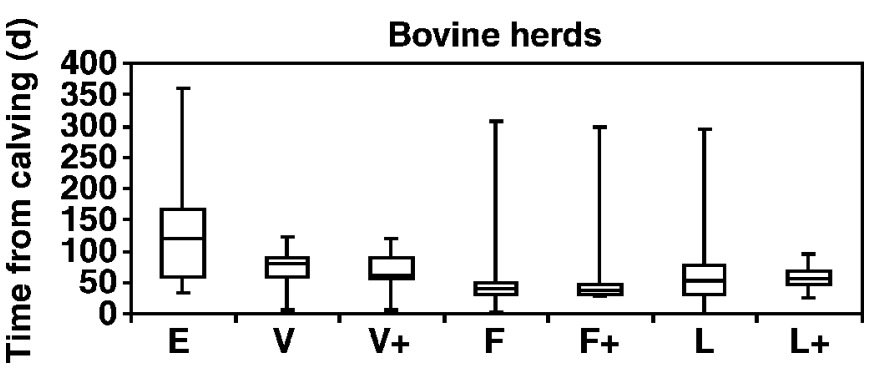

Figure 1. Median and quartile of the delay in days between the beginning of the study and the calving of the cows of the control herd (E), or of the infected herds $(\mathrm{V}, \mathrm{F}, \mathrm{L})$, according to their shedding of Coxiella burnetii. The lines represent the greatest and least delay between parturition and wk 0 . No significant difference was observed between the tested cows (V, F, L) and those shedding C. burnetii (V+, $\mathrm{F}+, \mathrm{L}+$ ).

\section{Statistical Tests}

Significant differences between groups were assessed by the Kruskall-Wallis test. Results were considered significant when $P<0.05$.

\section{RESULTS}

\section{Herd Selection and Clinical Signs}

All of the studied bovine herds were from northwest France. None of them presented with abortion, but all of them, including the negative herd, had reproductive disorders such as infertility and metritis. In herd V, which was previously vaccinated against bovine viral diarrhea, respiratory manifestations were observed in addition to metritis. Mastitis and metritis were the main pathologies in herd F. Herd F and the control herd E comprised only dairy cows (86 and 110 cows, respectively). The other 2 herds had small numbers of dairy cows (40 and 55, respectively) in large bovine herds (250 and 300 animals, respectively). The tested cows had calved from 0 to $421 \mathrm{~d}$ before the beginning of the study (Table 2, Figure 1).

The 4 selected caprine herds (Table 2) were located in southeast France. The negative caprine herd was managed traditionally and did not present any abortion cases. Herd $\mathrm{T}$ was found to be seropositive during a serological survey, whereas herd R, comprising 350 dairy goats, was thought to be the source of an outbreak of human $\mathrm{Q}$ fever 3 yr earlier. At the time of this study, the bulk tank milk samples of this herd remained PCR positive for $>3$ mo. Herd D comprised 310 dairy goats, in which 268 kiddings, 10 abortions, 21 stillbirths, and the delivery of 120 unviable kids were observed. They were assigned to $\mathrm{Q}$ fever due to the shedding of $C$. burnetii.

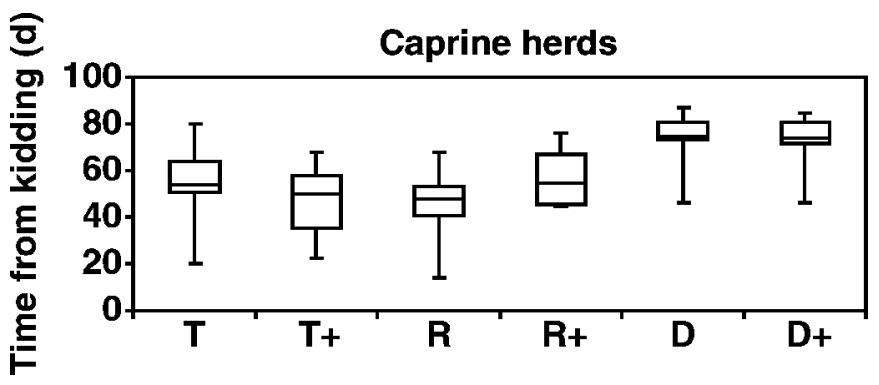

Figure 2. Median and quartile of the delay in days between the beginning of the study and the kidding of the goats of the infected herds. The lines represent the greatest and least delay between parturition and wk 0 . No significant difference was observed between the tested goats $(\mathrm{T}, \mathrm{R}, \mathrm{D})$ and those shedding Coxiella burnetii $(\mathrm{T}+$, $\mathrm{R}+, \mathrm{D}+$ ).

The 4 ovine flocks were more difficult to select. In the first test of the bulk tank milk, samples from 80 seropositive flocks were found to be PCR negative using protocol C. One year later, in another area of southwest France, bulk tank milk samples from 7 sheep flocks were PCR positive by protocol A.

Protocol A was more sensitive, especially for bovine and ovine milk, because large numbers of Coxiella were in the cream after centrifugation (Table 3). Indeed, although they were positive at the time of selection, all the bulk milk samples of bovine herd V were PCR negative by protocol $\mathrm{C}$, and those of bovine herd $\mathrm{F}$ became PCR positive again on wk 6 when tested using protocol A.

Ovine flocks $\mathrm{H}$ and $\mathrm{M}$ (comprising respectively, 150 and 250 dairy ewes) presented a high rate of abortions (10 and 25\% respectively), which were ascribed to $Q$ fever due to the serological titers of the aborted ewes. There was a $<5 \%$ abortion rate among the 150 dairy ewes of the ovine flock B.

The negative ovine flock, comprising 260 dairy ewes, was selected from the same area as the positive flock.

\section{Shedding of C. burnetii}

Contrary to expectation, for all ruminant species, the shedding of $C$. burnetii could not be related to parturition. Indeed, no significant difference was observed in the delay between parturition and the beginning of the experiment, between the PCR-positive animals and the tested animals (Figures 1 to 3 ), including bovine herds $\mathrm{F}$ and $\mathrm{L}$, in which cows were tested very close to calving. Moreover, some animals began to shed on wk 8 or wk 12. However, the shedding of $C$. burnetii differed according to species and among the herds of the same species, except for the ovine flocks.

Shedding of C. burnetii in Ovine Flocks. The 3 ovine flocks were heavily infected and shed bacteria 


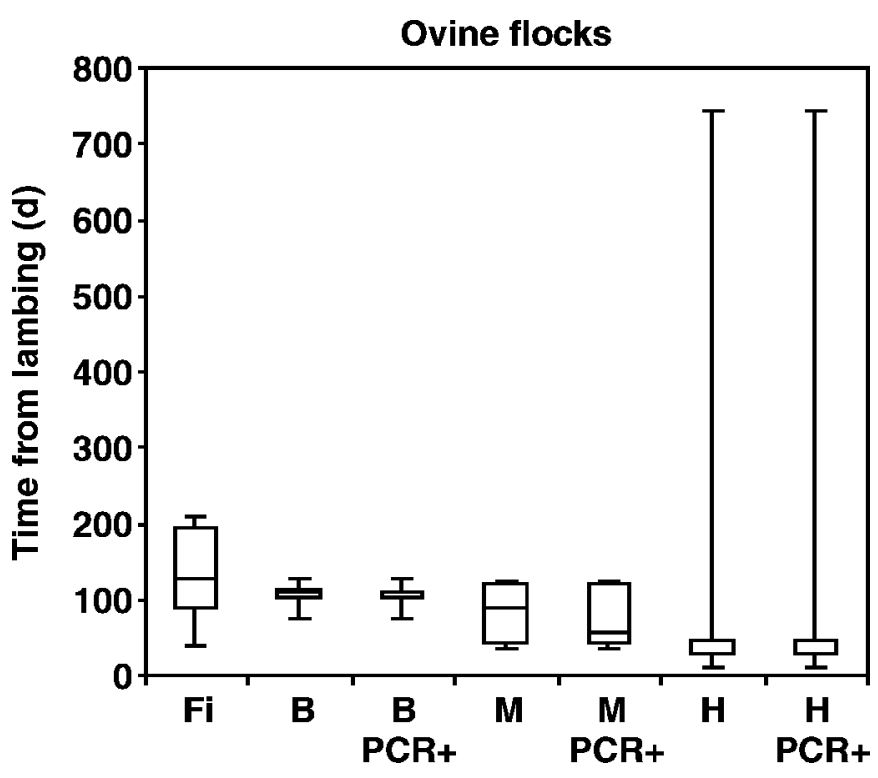

Figure 3. Median and quartile of the delay in days between the beginning of the study and the lambing of the ewes of the control flock $(\mathrm{Fi})$ or of the infected flocks. The lines represent the greatest and least delay between parturition and wk 0 . No significant difference was observed between the tested sheep (B, M, H) and those shedding Coxiella burnetii (B PCR+, M PCR+, H PCR+).

mainly in feces, in vaginal mucus, and, to a lesser extent, in milk (Table 4). However, no ewe shed C. burnetii constantly in milk, and no ovine milk sample was positive from wk 8,12 , and 14 in flocks $\mathrm{B}, \mathrm{H}$, and $\mathrm{M}$, respec- tively. All of the tested ewes of flock $\mathrm{H}(\mathrm{n}=30)$ excreted C. burnetii in feces, and one-half of them were still shedding the bacteria through this route in wk 8. Most of the ewes shed C. burnetii by at least 2 routes (Table 5). In flock H, no ewe shed $C$. burnetii by a single route.

Shedding of C. burnetii in Bovine Herds. Unlike the sheep, the cows did not shed $C$. burnetii in their feces. In addition, few cows (5/95) excreted the bacteria in their vaginal mucus (Table 4), but most of them excreted $C$. burnetii in milk. The shedding in bovine milk lasted through wk 16; on wk 16, the bulk milk samples of herds $\mathrm{F}$ and $\mathrm{L}$ were still PCR positive, and 1 cow each in herds $\mathrm{V}$ and $\mathrm{L}$, and 7 in herd F, excreted C. burnetii in milk. The longest duration of shedding after calving was 411, 170, and $152 \mathrm{~d}$ in herds F, V, and $L$, respectively. The greatest percentage of cows shedding C. burnetii in milk was observed in herd $\mathrm{V}$, but the cows excreted the bacteria intermittently. Among herd $\mathrm{L}$, in addition to the 5 cows that excreted C. burnetii in just one sample of milk, one cow excreted the bacteria intermittently between wk 1 and 16, and the other shed the bacteria in milk consistently from wk 0 to 12 . This cow also excreted $C$. burnetii in vaginal mucus. The 2 other cows that shed $C$. burnetii in milk and vaginal mucus (Table 5) had more than 1 PCRpositive milk sample. In herd F, 6 cows shed $C$. burnetii regularly in milk.

Shedding of C. burnetii in Caprine Herds. As in the bovine herds, milk was the main route of bacterial

Table 4. Shedding of Coxiella burnetii

\begin{tabular}{|c|c|c|c|c|c|c|c|}
\hline \multirow[b]{3}{*}{ Herd } & \multirow{2}{*}{\multicolumn{2}{|c|}{ Females, n }} & \multicolumn{5}{|c|}{ Shedding ${ }^{1}$} \\
\hline & & & \multirow{2}{*}{$\begin{array}{l}\text { Vaginal } \\
\text { mucus }\end{array}$} & \multirow[b]{2}{*}{ Feces } & \multirow[b]{2}{*}{ Milk } & \multirow{2}{*}{$\begin{array}{l}\text { Once, } \\
\text { in milk }\end{array}$} & \multirow{2}{*}{$\begin{array}{l}\text { Bulk tank } \\
\text { milk }+, \text { wk }^{3}\end{array}$} \\
\hline & Tested & $\mathrm{PCR}_{+}{ }^{2}$ & & & & & \\
\hline \multicolumn{8}{|l|}{ Bovine } \\
\hline $\mathrm{F}$ & 31 & 10 & 2 & 0 & 9 & 2 & 6 to 16 \\
\hline $\mathrm{L}$ & 31 & 8 & 2 & 0 & 6 & 4 & 2 to 3,6 to 16 \\
\hline $\mathrm{V}$ & 33 & 19 & 1 & 0 & 19 & 6 & None \\
\hline Total & 95 & 37 (38.9) & $5(13.5)$ & $0(0)$ & 34 (91.9) & $12(32.4)$ & $24^{4}$ \\
\hline \multicolumn{8}{|l|}{ Caprine } \\
\hline $\mathrm{D}$ & $60^{5}$ & 26 & 9 & 9 & 16 & 11 & 1 to 17 \\
\hline $\mathrm{R}$ & 30 & 4 & 0 & 0 & 4 & 4 & None \\
\hline $\mathrm{T}$ & 30 & 7 & 1 & 0 & 7 & 5 & 2 to 4,8 \\
\hline Total & 120 & 37 (30.8) & $10(27)$ & $9(24.3)$ & $27(73)$ & $20(54)$ & 16 \\
\hline \multicolumn{8}{|l|}{ Ovine } \\
\hline B & 30 & 28 & 16 & 18 & 10 & 7 & 1 to 4 \\
\hline $\mathrm{H}$ & 30 & 30 & 24 & 30 & 27 & 5 & 1,3 to 12 \\
\hline $\mathrm{M}$ & 30 & 27 & 23 & 18 & 18 & 7 & 1 to 12 \\
\hline Total & 90 & $85(94)$ & $63(74)$ & $66(78)$ & $55(65)$ & $19(22)$ & 19 \\
\hline
\end{tabular}

\footnotetext{
${ }^{1}$ Number in parentheses corresponds to the percentage of PCR+ females shedding C. burnetii by each route.

${ }^{2}$ Percentage of tested females shedding $C$. burnetii in vaginal mucus, feces, or milk is indicated in parentheses.

${ }^{3}$ Weeks in which the bulk tank milk samples were positive.

${ }^{4}$ Total number of bulk tank milk samples that were PCR+.

${ }^{5}$ Includes all goats, even those tested only in the first weeks.
} 
Table 5. Number (\%) of PCR+ females shedding Coxiella burnetii by 1, 2, or 3 routes

\begin{tabular}{|c|c|c|c|c|c|c|c|c|}
\hline Herd & $\begin{array}{l}\text { Milk } \\
\text { alone }\end{array}$ & $\begin{array}{l}\text { Vaginal } \\
\text { mucus } \\
\text { alone }\end{array}$ & $\begin{array}{l}\text { Feces } \\
\text { alone }\end{array}$ & $\begin{array}{l}\text { Milk + } \\
\text { feces }\end{array}$ & $\begin{array}{c}\text { Milk + } \\
\text { vaginal } \\
\text { mucus }\end{array}$ & $\begin{array}{l}\text { Vaginal } \\
\text { mucus } \\
+ \text { feces }\end{array}$ & $\begin{array}{l}\text { Milk, } \\
\text { vaginal } \\
\text { mucus, } \\
\text { feces }\end{array}$ & Total \\
\hline \multicolumn{9}{|l|}{ Bovine } \\
\hline $\mathrm{F}$ & 6 & 3 & 0 & 0 & 1 & 0 & 0 & 10 \\
\hline $\mathrm{L}$ & 6 & 1 & 0 & 0 & 1 & 0 & 0 & 8 \\
\hline V & 18 & 0 & 0 & 0 & 1 & 0 & 0 & 19 \\
\hline Total & $30(81.1)$ & $4(10.8)$ & 0 & 0 & $3(8.1)$ & 0 & 0 & 37 \\
\hline \multicolumn{9}{|l|}{ Caprine } \\
\hline $\mathrm{D}$ & 11 & 5 & 7 & 1 & 1 & 1 & 0 & 26 \\
\hline $\mathrm{R}$ & 4 & 0 & 0 & 0 & 0 & 0 & 0 & 4 \\
\hline $\mathrm{T}$ & 6 & 0 & 0 & 0 & 1 & 0 & 0 & 7 \\
\hline Total & $21(56.8)$ & $5(13.5)$ & 7 (18.9) & $1(2.7)$ & $2(5.4)$ & $1(2.7)$ & 0 & 37 \\
\hline \multicolumn{9}{|l|}{ Ovine } \\
\hline B & 4 & 6 & 4 & 4 & 0 & 8 & 2 & 28 \\
\hline $\mathrm{H}$ & 0 & 0 & 0 & 6 & 0 & 2 & 22 & 30 \\
\hline M & 3 & 1 & 1 & 0 & 5 & 7 & 10 & 27 \\
\hline Total & $7(8.2)$ & $7(8.2)$ & $5(5.9)$ & $10(11.8)$ & $5(5.9)$ & $17(20)$ & $34(40)$ & 85 \\
\hline
\end{tabular}

shedding in the caprine herds (Table 4). Two goats from herds $\mathrm{T}$ and $\mathrm{D}$ shed $C$. burnetii in milk throughout the experimental period (wk 0 to 16 for herd T and wk 6 to 16 for herd D), whereas in herd R, only 4 goats presented a transient $C$. burnetii shedding in milk, in wk 0 . In herd $\mathrm{D}$, of the 30 goats tested from wk 6, 19 excreted C. burnetii. Twelve shed C. burnetii in milk (4 constantly), 5 in vaginal mucus, and 5 in feces. Three goats shed the bacteria through 2 routes: 1 in vaginal mucus and feces, 1 in milk and vaginal mucus, and 1 in milk and feces. The percentage of PCR-positive goats shedding the bacteria in vaginal mucus and feces was lower than the percentage of PCR-positive ewes. In addition, no goat shed $C$. burnetii through all 3 routes.

\section{Relationship Between Coxiella burnetii Shedding and Serological Response}

The percentage of seropositive females was very low in the ovine flocks B and M, even if they were heavily infected. This proportion remained low when the ELISA cut-off was decreased to 40 as recommended by World Organisation for Animal Health (OIE, 2004; Table 6). The percentage of females shedding $C$. burnetii that were seropositive was $<10 \%$ in these 2 ovine flocks.

In bovine herd $\mathrm{V},<35 \%$ of the cows shedding C. burnetii were seropositive. In addition, in herd $\mathrm{V}$, the only cow that shed C. burnetii in vaginal mucus $113 \mathrm{~d}$ after calving was seronegative. This cow shed $C$. burnetii in milk for $155 \mathrm{~d}$. The 3 other cows that shed the bacteria for almost 5 mo $(144,155$, and $170 \mathrm{~d})$ were seropositive, as were the 2 cows that shed frequently in milk from wk 1 to 6 . In bovine herd $\mathrm{F}$, only one cow shedding $C$. burnetii was seronegative. It shed the bacteria in vaginal mucus alone in wk 8 (109 d after calving). Similarly, in herd $\mathrm{L}$, the 3 cows that were seronegative shed the bacteria in just one sample: 1 in vaginal mucus at wk 8 (106 d after calving), and the 2 others in milk at wk 2 and wk 8 ( 89 and $162 \mathrm{~d}$ after calving, respectively).

In caprine herd $\mathrm{D}$, over half of the goats that shed the bacteria mainly in vaginal mucus or feces were seropositive, as were the 4 goats that shed $C$. burnetii regularly in milk.

Twenty-three females became PCR-positive during the study. Twenty-two of them (14 cows belonging to the 3 bovine herds, 4 goats from caprine herd T, and 4 ewes belonging to ovine flocks $\mathrm{H}$ and $\mathrm{M}$ ) were already seropositive in wk 0 . Only one cow belonging to bovine herd L, which started to shed C. burnetii in milk in wk 6 , presented a seroconversion in wk 8 . Sixteen other seroconversions were observed between wh 0 and 8: 1 in each of bovine herds $\mathrm{V}$ and $\mathrm{F}$ and ovine flock $\mathrm{H}, 2$ in ovine flock B, 3 in bovine herd $\mathrm{L}$ and caprine herd $\mathrm{T}$, and 5 in caprine herd $\mathrm{R}$. These females were PCR negative except for the 3 ewes, which shed the bacteria in feces in wk 0 , and 1 goat in caprine herd $R$, which shed the bacteria in milk in wk 0 .

\section{Relationship Between Coxiella burnetii Shedding and Antibody Response in Milk}

The detection of antibodies in milk increased the number of ELISA-positive females in ovine flocks B and $\mathrm{M}$ (but not in flock $\mathrm{H}$ ) slightly, particularly those shedding $C$. burnetii in milk (Table 6 ). When the detection of antibodies in individual milk was performed each week in herds $\mathrm{V}$ and $\mathrm{T}$, the milk samples of the females that shed C. burnetii transiently in milk became ELISA positive several weeks after shedding. However, those that shed frequently in milk were sero- 
Table 6. Relationship between antibody responses (optical density, OD, \%) and shedding of Coxiella burnetii of the tested females in the different herds

\begin{tabular}{|c|c|c|c|c|c|c|c|c|c|c|c|c|c|}
\hline \multirow{2}{*}{ Herd } & \multirow{2}{*}{$\begin{array}{c}\text { Tested } \\
\text { females, } \\
n\end{array}$} & \multicolumn{6}{|c|}{ ELISA, $\mathrm{n}$} & \multicolumn{4}{|c|}{$\begin{array}{l}\text { Number of females } \\
\text { PCR+ presenting }\end{array}$} & \multirow{2}{*}{\multicolumn{2}{|c|}{$\begin{array}{l}\text { Bulk tank milk } \\
\text { PCR+ and } \\
\text { ELISA OD \% }\end{array}$}} \\
\hline & & \multicolumn{2}{|c|}{ Serum with OD \% } & \multicolumn{2}{|c|}{ Milk with OD \% } & \multicolumn{2}{|c|}{ Serum \& Milk } & \multicolumn{2}{|c|}{ Serum with OD \% } & \multicolumn{2}{|c|}{ Milk with OD \% } & & \\
\hline \multicolumn{14}{|l|}{ Bovine } \\
\hline $\mathrm{F}$ & 31 & $13(42)^{1}$ & $13(42)^{1}$ & $\mathrm{NT}^{2}$ & NT & 13 & NT & $9(90)^{3}$ & $9(90)^{3}$ & NT & NT & NT & NT \\
\hline $\mathrm{L}$ & 31 & 9 (29) & $9(29)$ & NT & NT & NT & NT & $6(67)$ & $6(67)$ & NT & NT & NT & NT \\
\hline \multicolumn{14}{|l|}{ Caprine } \\
\hline $\mathrm{D}$ & $60^{5}$ & $29^{6}(42)$ & $37 \quad(54)$ & NT & NT & NT & NT & $16(53)$ & $19(63)$ & NT & NT & NT & NT \\
\hline $\mathrm{R}$ & 30 & $12(36)$ & $18(60)$ & NT & NT & NT & NT & $3(75)$ & 4 (100) & NT & NT & NT & NT \\
\hline $\mathrm{T}$ & 30 & 21 & $23(77)$ & $20^{7}(67)$ & $25^{7}(83)$ & 16 & 20 & $6(86)$ & $7(100)$ & $6(86)$ & $7(100)$ & $4 / 9$ & $4 / 9$ \\
\hline Total & 120 & $62(52)$ & $78(65)$ & 20 & 25 & 16 & 20 & $25(61)$ & $30(81)$ & 6 & 7 & 4 & 4 \\
\hline \multicolumn{14}{|l|}{ Ovine } \\
\hline B & 30 & $2(6)$ & $4(13)$ & $6^{8}(20)$ & $10(33)$ & 0 & 4 & $2(7)$ & $4(14)$ & $6(21)$ & $8(29)$ & 1 & 1 \\
\hline
\end{tabular}

${ }^{1}$ Percentage of tested females with this OD \% was indicated in parentheses.

${ }^{2} \mathrm{NT}=$ not tested.

${ }^{3}$ Number in parentheses corresponds to the percentage of PCR + females with this OD in ELISA.

${ }^{4}$ Tested between wk 2 and 16 .

${ }^{5}$ Includes all the goats even those which were tested only in the first week

${ }^{6}$ Serological responses were weak; only 5 goats had an OD percentage $>100$.

${ }^{7}$ Tested between wk 0 to 16 .

${ }^{8}$ Tested at the same time than serum samples, wk 0 and 8 .

${ }^{9}$ When the cut-off was 40 instead of 50 the bulk tank milk samples of ovine flocks became ELISA-positive, except those taken on wk 0 from flock B.

positive, and their milk samples were constantly ELISA positive.

The bulk tank milk samples of caprine herd $\mathrm{T}$ and bovine herd $\mathrm{V}$ were ELISA positive throughout the study.

\section{Control Herds}

As expected, none of the goats in the negative control herd was seropositive or shed the bacteria. The 30 cows in the bovine herd were seronegative, although 3 presented a very weak PCR signal from milk. In spite of 2 successive bulk tank milk samples that tested PCRnegative, and 10 seronegative serum samples, 2 ewes from the negative control flock shed C. burnetii in their feces, and another was seropositive.

\section{DISCUSSION}

The data presented in this study revealed that ovine flocks shed C. burnetii mainly in feces and vaginal mucus, whereas in bovine herds, these routes of excretion were rare. This difference could explain why, in many areas, outbreaks of human $\mathrm{Q}$ fever are more often related to small ruminants than to bovines. However, in the bovine herds investigated in this study, the cows did not abort from $\mathrm{Q}$ fever. Thus, it would be necessary to analyze the routes of $C$. burnetii shedding in cows that aborted before concluding that $C$. burnetii shedding in bovine feces is truly minor. Indeed, in a study of C. burnetii excretion in 242 cows belonging to 31 herds in which abortions due to $C$. burnetii were recorded, the 3 routes of shedding (vaginal, fecal, or mammary) were equivalent (Guatteo et al., 2006). In addition, in the caprine herd $\mathrm{D}$ in which abortions due to $\mathrm{Q}$ fever were reported, 34.6\% of the goats that shed the bacteria shed them in vaginal mucus or feces, unlike the goats in the 2 asymptomatic herds.

Nevertheless, bacterial shedding in milk seems to be less widespread in ewes than in asymptomatic cows. This shedding could last several months after the calving and, surprisingly, it was not always the cows closer to calving that shed C. burnetii most frequently. Shedding of $C$. burnetii in milk taken from dairy cows that did not abort was previously reported in Japan (To et al., 1998) and in the United States (Kim et al., 2005). In this latter study, 316 bulk tank milk samples from several herds revealed a very high prevalence of shedding over $3 \mathrm{yr}$. In addition, the authors also investigated C. burnetii shedding by 5 PCR-positive cows over 4 wk. 
In contrast, in our study, we chose to follow 95 cows from only 3 herds. Most of these cows were PCR negative at the beginning of the study, and they started to shed bacteria in milk at different times. Some of them were latently infected before the beginning of the study, as they were seropositive. Two of them ( 1 cow and 1 goat) became infected during the study, as indicated by their seroconversion after they started to shed the bacteria in milk. Five cows and 7 goats that were seronegative in wk 0 became seropositive in wk 8 without shedding the bacteria, suggesting that $C$. burnetii circulated in the herds and that even asymptomatic bovine herds should be considered reservoirs of the bacteria capable of transmitting the disease to other animal species or to humans.

The identification of negative ovine flocks was difficult and required numerous analyses. The antibodies in milk can be due to a local synthesis against an antigenic stimulation of the mammary gland by $C$. burnetii shed in milk, but antibodies usually result in the transfer of immunoglobulin from blood to milk. Therefore, the milk-antibody titer cannot be used for the detection of C. burnetii milk-shedder females. However, bulk tank milk samples provide a useful tool with which to investigate the sanitary grade of bovine and caprine herds by checking for the presence of $C$. burnetii by PCR and of antibodies by ELISA, in addition to the analysis of serum samples of at least $10 \%$ of the animals in the herds. To be efficient, these analyses should be performed several times, and the ELISA must be assessed using an antigen isolated from ruminants. In this study, several animals shedding Coxiella, as indicated by PCR, were seronegative using the Nine Mile antigen, even with a cut-off at $40 \%$ of OD, but they became seropositive using an ELISA based on antigens from C. burnetii isolated from ruminants (unpublished data). In herds presenting with PCR-positive bulk tank milk, pools of 10 milk samples can be tested by PCR to identify the shedding animals. If shedders are not very numerous they can be eliminated, and the other animals should be vaccinated with phase I vaccine. Indeed, the phase I vaccine Coxevac (Ceva Santé Animale, Libourne, France) protects very efficiently against abortion and has been shown to prevent bacterial shedding in vaginal mucus, feces, and particularly milk (Arricau-Bouvery et al., 2005). It would be very useful to vaccinate the herds in the vicinity of infected flocks.

\section{ACKNOWLEDGMENTS}

This work was supported by DGAL (Direction Générale de l'Alimentation) Grant no. R01/03 of the AQS (Aliment Qualité et Sécurité - Food Quality and Safety) program.

\section{REFERENCES}

Arricau-Bouvery, N., A. Souriau, C. Bodier, P. Dufour, E. Rousset, and A. Rodolakis. 2005. Effect of vaccination with phase I and phase II Coxiella burnetii vaccines in pregnant goats. Vaccine 23:4392-4402.

Arricau-Bouvery, N., A. Souriau, P. Lechopier, and A. Rodolakis. 2003. Experimental Coxiella burnetii infection in pregnant goats: Excretion routes. Vet. Res. 34:423-433.

Benson, W. W., D. W. Brock, and J. Mather. 1963. Serologic analysis of a penitentiary group using raw milk from a $\mathrm{Q}$ fever infected herd. Public Health Rep. 78:707-710.

Berri, M., N. Arricau-Bouvery, and A. Rodolakis. 2003a. PCR-based detection of Coxiella burnetii from clinical samples. Pages 153160 in Methods in Molecular Biology. K. Sachse and J. Frey, ed. Humana Press Inc., Totowa, NJ.

Berri, M., K. Laroucau, and A. Rodolakis. 2000. The detection of Coxiella burnetii from ovine genital swabs, milk and fecal samples by the use of a single touchdown polymerase chain reaction. Vet. Microbiol. 72:285-293.

Berri, M., E. Rousset, J. L. Champion, N. Arricau-Bouvery, P. Russo, M. Pépin, and A. Rodolakis. 2003b. Ovine manure used as a garden fertiliser as a suspected source of human $\mathrm{Q}$ fever. Vet. Rec. 153:269-270.

Berri, M., E. Rousset, C. Héchard, J. L. Champion, P. Dufour, P. Russo, and A. Rodolakis. 2005. Progression of Q fever and Coxiella burnetii shedding in milk after an outbreak of enzootic abortion in a goat herd. Vet. Rec. 156:548-549.

Berri, M., A. Souriau, M. Crosby, D. Crochet, P. Lechopier, and A. Rodolakis. 2001. Relationships between the shedding of Coxiella burnetii, clinical signs and serological responses of 34 sheep. Vet. Rec. 148:502-505.

Bildfell, R. J., G. W. Thomson, D. M. Haines, B. J. McEwen, and N. Smart. 2000. Coxiella burnetii infection is associated with placentitis in cases of bovine abortion. J. Vet. Diagn. Invest. 12:419-425.

Fishbein, D. B., and D. Raoult. 1992. A cluster of Coxiella burnetii infections associated with exposure to vaccinated goats and their unpasteurized dairy products. Am. J. Trop. Med. Hyg. 47:35-40.

Guatteo, R., F. Beaudeau, M. Berri, A. Rodolakis, A. Joly, and H. Seegers. 2006. Shedding routes of Coxiella burnetii in dairy cows: Implications for detection and control. Vet. Res. 37:827-833.

Hatchette, T. F., R. C. Hudson, W. F. Schlech, N. A. Campbell, J. E. Hatchette, S. Ratnam, D. Raoult, C. Donovan, and T. J. Marrie. 2001. Goat-associated Q fever: A new disease in Newfoundland. Emerg. Infect. Dis. 7:413-419.

Kim, S. G., E. H. Kim, C. J. Lafferty, and E. Dubovi. 2005. Coxiella burnetii in bulk tank milk samples, United States. Emerg. Infect. Dis. 11:619-621.

Lang, G. H. 1990. Coxiellosis (Q fever) in animals. Pages 23-48 in Q fever: The disease. T. J. Marrie, ed. CRC Press, Boca Raton, FL.

Lyytikäinen, O., T. Ziese, B. Schwartländer, P. Matzdorff, C. Kuhnhen, C. Jäger, and L. Petersen. 1998. An outbreak of sheep-associated $\mathrm{Q}$ fever in a rural community in Germany. Eur. J. Epidemiol. 14:193-199.

Masala, G., R. Porcu, G. Sanna, G. Chessa, G. Cillara, V. Chisu, and S. Tola. 2004. Occurence, distribution and role in abortion of Coxiella burnetii in sheep and goats in Sardinia, Italy. Vet. Microbiol. 99:301-305.

Maurin, M., and D. Raoult. 1999. Q fever. Clin. Microbiol. Rev. 12:518-553.

Moore, J. D., B. C. Barr, B. M. Daft, and M. T. O'Connor. 1991. Pathology and diagnosis of Coxiella burnetii in a goat herd. Vet. Pathol. 28:81-84.

Muramatsu, Y., M. Maruyama, T. Yanase, H. Ueno, and C. Morita. 1996. Improved method of preparation of samples for the polymerase chain reaction for detection of Coxiella burnetii in milk, using immunomagnetic separation. Vet. Microbiol. 51:179-185.

OIE. 2004. Manual of Diagnostic Tests and Vaccines for Terrestrial Animals Part 2, Section 2.2, Chapter 2.2 10. http://www.oie.int/ fr/normes/mmanual/A_00049.htm. 
Palmer, N. C., M. Kierstead, D. W. Key, J. C. Williams, M. G. Peacock, and H. Vellend. 1983. Placentitis and abortion in goats and sheep in Ontario caused by Coxiella burnetii. Can. Vet. J. 24:60-61.

Rehácek, J., E. Kocianová, E. Kovácová, B. Kapitancik, A. Jurcina, O. Nad, and P. Licko. 1998. Occurence of bovine coxiellosis in the district of Bardejov, Eastern Slovakia. Vet. Med.-Czech 43:325-330.

Tissot-Dupont, H., S. Torres, M. Nezri, and D. Raoult. 1999. Hyperendemic focus of Q fever related to sheep and wind. Am. J. Epidemiol. 150:67-74.

To, H., K. K. Htwe, N. Kako, H. J. Kim, T. Yamaguchi, H. Fukushi, and K. Hirai. 1998. Prevalence of Coxiella burnetii infection in dairy cattle with reproductive disorders. J. Vet. Med. Sci. 60:859-861.
To, H., K. K. Htwe, N. Yamasaki, G. Q. Zhang, M. Ogawa, T. Yamaguchi, H. Fukushi, and K. Hirai. 1995. Isolation of Coxiella burnetii from dairy cattle and ticks, and some characterization of the isolates in Japan. Microbiol. Immunol. 39:663-671.

Welsh, H. H., E. H. Lennette, F. R. Abinanti, and J. F. Winn. 1957. Airborne transmission of $\mathrm{Q}$ fever: The role of parturition in generation of infective aerosol. Ann. N.Y. Acad. Sci. 70:528-540.

Willems, H., D. Thiele, R. Frhlich-Ritter, and H. Krauss. 1994. Detection of Coxiella burnetii in cow's milk using the polymerase chain reaction (PCR). J. Vet. Med. Ser. B 41:580-587.

Woernle, H., C. Limouzin, K. Muler, and M. P. Durand. 1985. La fièvre Q bovine. Effets de la vaccination et de l'antibiothérapie sur l'évolution clinique et l'excrétion de Coxiella dans le lait et les sécrétions utérines. Bull. Acad. Vet. Fr. 58:91-100. 